\title{
Review
}

\section{Emerging roles for lipids in non-apoptotic cell death}

\author{
L Magtanong ${ }^{1}$, PJ Ko ${ }^{1}$ and SJ Dixon ${ }^{*, 1}$
}

Non-apoptotic regulated cell death $(R C D)$ is essential to maintain organismal homeostasis and may be aberrantly activated during certain pathological states. Lipids are emerging as key components of several non-apoptotic RCD pathways. For example, a direct interaction between membrane phospholipids and the pore-forming protein mixed lineage kinase domain-like (MLKL) is needed for the execution of necroptosis, while the oxidative destruction of membrane polyunsaturated fatty acids (PUFAs), following the inactivation of glutathione peroxidase 4 (GPX4), is a requisite gateway to ferroptosis. Here, we review the roles of lipids in the initiation and execution of these and other forms of non-apoptotic cell death. We also consider new technologies that are allowing for the roles of lipids and lipid metabolism in RCD to be probed in increasingly sophisticated ways. In certain cases, this new knowledge may enable the development of therapies that target lipids and lipid metabolic processes to enhance or suppress specific non-apoptotic RCD pathways.

Cell Death and Differentiation (2016) 23, 1099-1109; doi:10.1038/cdd.2016.25; published online 11 March 2016

\section{Facts}

- Emerging evidence suggests important roles for lipids and lipid metabolism in several non-apoptotic cell death pathways.

- Non-apoptotic cell death can be triggered by specific fatty acids.

- Specific lipids in the plasma membrane are essential for the execution of non-apoptotic cell death.

- Depletion of specific lipids is required for at least one form of non-apoptotic RCD.

\section{Open Questions}

- What molecular mechanisms link the accumulation of specific lipids to the induction of non-apoptotic RCD?

- Do lipids or the disruption of lipid metabolic pathways trigger non-apoptotic RCD pathways in unusual ways, or perhaps cause new types of non-apoptotic RCD?

- Can diseases of lipid metabolism teach us anything about how lipids trigger or mediate non-apoptotic cell death?

- Can we specifically target lipid-dependent aspects of nonapoptotic RCD to treat disease?
Regulated cell death (RCD) is crucial for development and the maintenance of homeostasis. ${ }^{1,2}$ In addition to apoptosis, in recent years many non-apoptotic RCD pathways have been described, including necroptosis, pyroptosis, parthanatos, ferroptosis and several others. ${ }^{2-7}$ These pathways are known or thought to contribute to cell death following viral infection, bacterial infection, neurodegeneration, ischemia-reperfusion injury to various tissues and other pathological processes, and therefore present new targets for therapeutic intervention. ${ }^{8,9}$ Understanding the regulation of non-apoptotic RCD pathways is therefore of great biomedical interest.

Lipids and lipid metabolism are emerging as key regulators of cell survival, ${ }^{10}$ proliferation, ${ }^{11}$ stress responses, ${ }^{12}$ and as described in this review, cell death. Six categories of lipids, each with distinguishing structural features, are normally present in mammalian cells: fatty acids (FAs), sphingolipids, glycerolipids, glycerophospholipids, prenol lipids, and sterol lipids (Figure 1a). ${ }^{13}$ Each category of lipids encompasses diverse molecular species. For example, glycerophospholipids, a major constituent of biological membranes, can be subdivided into those containing choline (phosphatidylcholine, PC), inositol (phosphatidylinositol, PI), serine (phosphatidylserine, PS), and other head groups, some of which can be

\footnotetext{
'Department of Biology, Stanford University, 337 Campus Drive, Stanford, CA, USA

*Corresponding author: S Dixon, Department of Biology, Stanford University, Room 104, 337 Campus Drive, Stanford, CA 94305, USA. Tel: +6507251798; Fax: +6507235920; E-mail: sjdixon@stanford.edu

Abbreviations: RCD, regulated cell death; MLKL, mixed lineage kinase domain-like; PUFA, polyunsaturated fatty acid; GPX4, glutathione peroxidase 4; FAs, fatty acids; PC, phosphatidylcholine; PI, phosphatidylinositol; PS, phosphatidylserine; PIPs, phosphatidylinositol phosphates; SFA, saturated fatty acid; MUFA, monounsaturated fatty acid; LA, linoleic acid; ER, endoplasmic reticulum; BAX, BCL2-associated X protein; BAK, BCL2-antagonist/killer 1; CoA, coenzyme A; ACC1, acetyl-CoA carboxylase 1; ACC2, acetyl-CoA carboxylase 2; FASN, fatty acid synthase; SCD, stearoyl-CoA desaturase; CPT1, carnitine palmitoyltransferase 1; OA, oleic acid; LMP, lysosomal membrane permeability; Spi2a, serine protease inhibitor 2a; MFGs, milk fat globules; LPS, lipopolysaccharide; Nec-1, necrostatin-1; TLR4, Toll-like receptor; TRIF, TIR-domain-containing adapter-inducing interferon- $\beta$; TOFA, 5 -(tetradecyloxy)-2-furoic acid; TNF- $\alpha$, tumor necrosis factor-alpha; RIPK1, receptor-interacting serine/ threonine-protein kinase 1; RIPK3, receptor-interacting serine/threonine-protein kinase 3; PIKfyve, phosphoinositide kinase; FYVE, finger containing; PTEN, phosphatase and tensin homolog; PAMPs, pathogen-associated molecular patterns; DAMPs, damage-associated molecular patterns; NLRP3, nucleotide-binding oligomerization domain-like receptor 3; ROS, reactive oxygen species; GSH, glutathione; L-OOH, lipid peroxide; L-OH, lipid alcohol; L-O•, lipid radical; AA, arachidonic acid; ACSL4, acylCoA synthetase long-chain family member 4; LPCAT3, lysophosphatidylcholine acyltransferase 3; Fer-1, ferrostatin-1; Vit. E, vitamin E; 4-HNE, 4-hydroxynonenal; ACAD11, acyl-CoA dehydrogenase family member 11; SRS, stimulated Raman scattering; PLs, phospholipids; FFAST, free fatty acid stable isotope tagging; LC-MS/MS, liquid chromatography-tandem mass spectrometry; 24S-OHC, 24(S)-hydroxycholesterol; mTOR, mechanistic target of rapamycin; SMAC, second mitochondrial-derived activator of caspases; PFTs, pore-forming toxins; SREBP1/2, sterol-regulatory element-binding proteins 1 and 2; HMGCR, 3-hydroxy-3-methylglutaryl-CoA reductase; LDs, lipid droplets; ACAT1, acyl-CoA:cholesterol acyltransferase 1; HETE, hydroxyeicosatetraenoic acid; IEMs, inborn errors of metabolism

Received 18.12.15; revised 08.2.16; accepted 10.2.16; Edited by WB Derry; published online 11.3.16
} 


Fatty acyl/acid

b

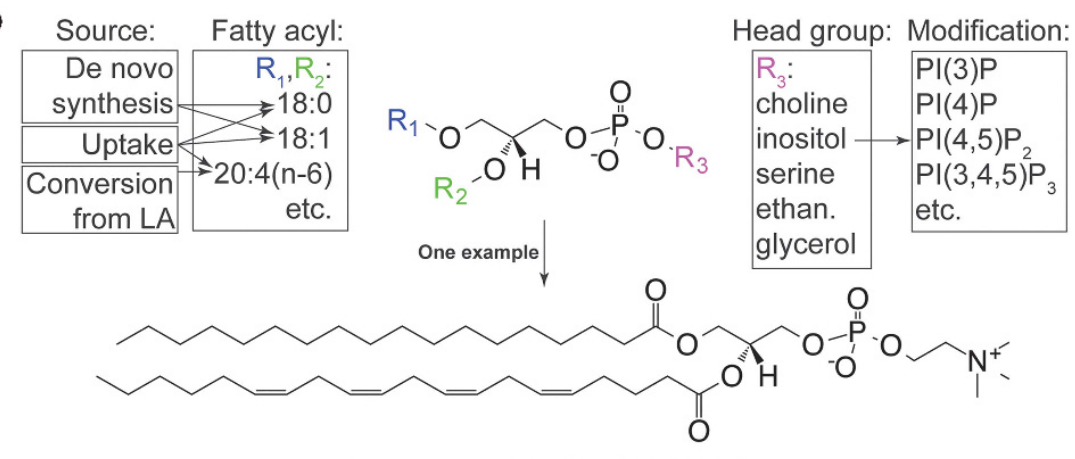

Phosphatidylcholine (18:0/20:4)

Figure 1 Overview of lipids and lipid diversity. (a) Six categories of lipids important for mammalian cell function (see also lipidmaps.org for more information). (b) An example of structural diversity in the glycerophospholipid class. Glycerophospholipids can be esterified at two positions $\left(R_{1}\right.$ and $R_{2}$, respectively) with distinct FAs. SFAs and MUFAs can be synthesized de novo or taken up from the environment. PUFAs are taken up from the environment or synthesized from essential PUFA precursors like linoleic acid (LA, 18:2n-6). The head group conjugated to the phosphate can be one of the several molecules (ethan.: ethanolamine). Inositol can be further modified by phosphorylation, generating additional diversity. The example molecule shows a PC conjugated to an SFA, stearic acid $\left(R_{1}=18: 0\right)$, and a PUFA, arachidonic acid $\left(R_{2}=20: 4 n-6\right)$

further modified (e.g., phosphorylation of PI to generate phosphatidylinositol phosphates (PIPs))(Figure 1b). Furthermore, each glycerophospholipid can contain esterified FAs with different chain lengths and degrees of unsaturation (corresponding to the number of double bonds in the FA chain), ultimately generating incredible structural diversity (Figure 1b). Indeed, it is likely that several thousand structurally distinct lipid species exist in mammalian cells (see lipidmaps.org). ${ }^{13,14}$ Together, these lipids have many roles in RCD, as triggers of cell death, as essential components needed for the operation of multi-step RCD pathways, and ultimately, as components of lipid membranes that are physically disrupted (i.e., breached) in various ways during cell death.

The roles of lipids in apoptotic cell death have been studied for some time, and provide a framework for understanding the various roles that lipids can play in non-apoptotic RCD. First, lipids can serve as a signal to initiate apoptosis or transduce an apoptotic signal. Thus, treatment of cells with the saturated fatty acid (SFA) palmitate $(16: 0$, annotations herein refer to the number of carbon atoms and points of unsaturation) can trigger apoptosis by causing endoplasmic reticulum (ER) stress, ${ }^{15}$ while ceramide (a sphingolipid; Figure 1a) accumulates in cancer cells exposed to pro-apoptotic signals (e.g., ultraviolet irradiation, the small molecule staurosporine) and has an enigmatic role in transducing this signal, perhaps by damaging intracellular membranes or the plasma membrane. ${ }^{16-18}$ Second, lipids have important accessory roles in the execution of apoptosis. For example, in the intrinsic apoptosis pathway, oligomerization of the pore-forming $\mathrm{BH} 3$ family members BCL2-associated X protein (BAX) and BCL2antagonist/killer 1 (BAK) on the mitochondrial outer 
membrane requires the lipids sphingosine-1-phosphate and hexadecenal as specific cofactors. ${ }^{19}$ Furthermore, downstream of BAX and BAK insertion into the mitochondrial outer membrane, oxidization of PUFA-rich mitochondrial cardiolipins (a class of glycerophospholipids synthesized in the mitochondrion) on the outer leaflet of the mitochondrial inner membrane promotes the release of cytochrome $\mathrm{C}$ and other key apoptotic effectors from the mitochondria into the cytosol. $^{20,21}$ Third, lipid-containing membranes are key targets for modification and destruction during apoptosis. As noted above, mitochondrial outer membrane permeabilization is an essential step during the intrinsic apoptotic cascade, ${ }^{22}$ while caspase-mediated cleavage of lipid flippases and scramblases at the plasma membrane leads to enrichment of PS on the outer leaflet of the plasma membrane, a signal essential for the recognition and phagocytosis of apoptotic cells. ${ }^{23-27}$ These examples highlight the multitude of important roles played by lipids and lipid metabolism in apoptotic RCD.

What roles do lipids play in non-apoptotic RCD? Recent studies suggest important roles for lipids and lipid metabolism in both triggering and executing non-apoptotic RCD. These roles are distinct from those observed during apoptosis but involve similar themes, including a role for certain lipids as triggers of cell death and the centrality of membrane lipid damage to the final lethal process. In this review, we highlight a selection of these emerging links between lipids and nonapoptotic RCD in mammalian cells. We also highlight several areas where our knowledge of the connection between lipids and non-apoptotic RCD is wanting and where new technologies may be useful in studying the roles of lipids in RCD.

\section{Triggering of non-apoptotic cell death by FAs}

FAs are simple lipids composed of elongated hydrocarbon chains with a terminal carboxylic acid (Figure 1a). FAs can be synthesized de novo (conjugated to coenzyme $A(C \circ A)$ as an acyl-CoA), liberated from existing lipids, such as glycerolipids and glycerophospholipids, by lipases (e.g., phospholipases), or taken up by the cell from extracellular sources. In de novo FA synthesis, the rate-limiting step is the conversion of acetylCoA to malonyl-CoA, the essential unit of FA elongation, by acetyl-CoA carboxylases 1 and 2 (ACC1 and ACC2). Fatty acid synthase (FASN) utilizes malonyl-CoA, acetyl-CoA, and NADPH to synthesize the saturated acyl-CoA palmitoyl-CoA (16:0). Palmitoyl-CoA can be further elongated by ERresident enzymes and desaturated by stearoyl-CoA desaturases (SCDs), for example converting stearoyl-CoA (18:0) to oleoyl-CoA (18:1n-9, where $n-x$ refers to the position of the first carbon-carbon double bond counting from the methyl end of the carbon chain). Acyl-CoAs can then be incorporated into existing lipids by a large family of acyl transferase enzymes. Acyl-CoAs can also be catabolized in mitochondria and peroxisomes through $\beta$-oxidation. Mitochondrial $\beta$-oxidation requires carnitine palmitoyltransferase 1 (CPT1)-mediated fatty acyl-CoA uptake into the mitochondria. Subsequent catabolism produces acetyl-CoA, $\mathrm{FADH}_{2}$, and $\mathrm{NADH}$, which can fuel the tricarboxylic acid cycle and ATP synthesis. Inhibition of de novo FA synthesis and catabolism is thought to trigger apoptosis, at least in cancer cells, where this has been
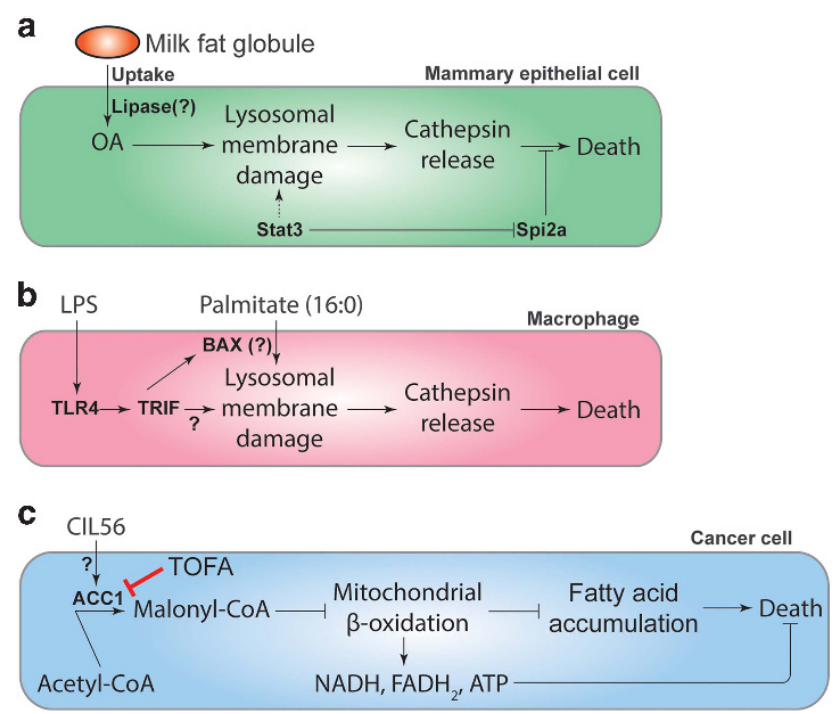

Figure 2 Lipids as triggers of non-apoptotic cell death. (a) During the process of post-lactational regression, mammary epithelial cells take up MFGs, a type of storage lipid. MFGs containing OA (18:1n-9) can damage lysosomal membranes, leading to the release of cathepsins and induction of non-apoptotic cell death. It is unclear whether lysosomal damage is triggered by $O A$ conjugated to the glycerol backbone or OA liberated from the glycerol backbone by a lysosomal lipase. Stat3 promotes this process in several ways, including enhancing the size (and potentially the sensitivity to damage) of the lysosomal membrane, upregulating the expression of cathepsins, and inhibiting the expression of the cathepsin inhibitor Spi2a. (b) In macrophages, LPS together with palmitate triggers lysosomal damage and non-apoptotic cell death. (c) A synthetic small molecule, CIL56, can trigger caspase-independent cell death that is suppressed by deleting ACACA, which encodes ACC1, or inhibiting ACC activity using TOFA. The lethal mechanism is unclear, but may involve the accumulation of malonyl-CoA and inhibition of mitochondrial $\beta$-oxidation, leading to the simultaneous accumulation of multiple FAs to toxic levels and/or depletion of the products of $\beta$-oxidation (NADH, FADH $\mathrm{F}_{2}$, ATP)

studied most extensively. ${ }^{28}$ Roles for these processes in nonapoptotic RCD are also now emerging.

Oleic acid as a trigger for cell death in mammary epithelial cells. An intriguing connection is emerging between the monounsaturated fatty acid (MUFA) oleic acid $(\mathrm{OA})$, lysosomal membrane permeability (LMP) and nonapoptotic RCD (Figure 2a). Lysosomes are intracellular organelles with an enigmatic connection to cell death, being linked to both apoptotic and non-apoptotic cell death in different cells and contexts. ${ }^{29,30}$ However, following pregnancy and weaning, a lysosome-mediated, non-apoptotic pathway is activated to return the milk-producing mammary epithelium to its pre-pregnancy state (i.e., post-lactational regression, also called involution). ${ }^{31,32}$ The transcription factor Stat3 is a key regulator of involution that promotes the physical expansion of the lysosome, upregulation of the lysosomal-resident protease cathepsins $B$ and $L$, and downregulation of serine protease inhibitor 2a (Spi2a), an endogenous serpin-family cathepsin inhibitor. Stat3 also controls a switch from a secretory state (during lactation) to a phagocytic state (during involution). In the phagocytic state, mammary cells phagocytize milk fat globules (MFGs) that contain high levels of OA-containing triacylglycerides. OA liberated from triacylglycerides in the lysosome triggers permeabilization of lysosomes and leakage of intralysosomal 
cathepsins $B$ and $L$ into the cytosol where they initiate caspase-independent cell death. How OA released from MFGs triggers lysosomal cathepsin leakage is not clear, but insertion of the OA chain, which is 'kinked' by a single point of unsaturation, into the lysosomal membrane may physically disrupt its integrity and help to open pores through which cathepsins can exit. How cathepsin release causes nonapoptotic cell death remains to be characterized.

Palmitate as a trigger for cell death in macrophages. A different interaction between lipids and the lysosome can trigger non-apoptotic RCD in macrophages. When these cells are exposed to palmitate in combination with lipopolysaccharide (LPS, a lipid-modified sugar found on the surface of Gram-negative bacteria), cells undergo an unusual form of non-apoptotic cell death that is not blocked by broadspectrum caspase inhibitors or the necroptosis inhibitor necrostatin-1 (Nec-1; Figure 2b). ${ }^{33,34}$ This pathway requires the LPS receptor Toll-like receptor 4 (TLR4) and the downstream component TIR-domain-containing adapter-inducing interferon- $\beta$ (TRIF), which primes lysosomes in an unknown way for palmitate-induced damage and cathepsin release. In the absence of LPS treatment, palmitate causes only minimal levels of cell death in these cells, and the link between palmitate, the TLR4-TRIF pathway, lysosomes, and cell death is obscure. It is known that palmitate, in complex with BAX, can induce LMP; ${ }^{35}$ it is therefore possible that TLR4-TRIF signaling could enhance $\mathrm{BAX}$ expression or deplete the cell of an endogenous BAX inhibitor, allowing a palmitate-BAX complex to cause lysosomal damage.

Generalized FA accumulation as a trigger for nonapoptotic cell death. Recently, an unusual example of how lipid accumulation can trigger non-apoptotic RCD has emerged from the study of a synthetic small molecule named CIL56 (Figure 2c). Treatment of human HT-1080 fibrosarcoma cells with CIL56 causes the accumulation of numerous SFAs, MUFAs, and PUFAs, and results in caspaseindependent RCD. ${ }^{36}$ Genetic screening identified ACACA (encoding ACC1) as a gene essential for ClL56-induced cell death. ${ }^{36}$ Moreover, a small molecule ACC inhibitor, 5-(tetradecyloxy)-2-furoic acid (TOFA), prevents both CIL56induced cell death and the observed changes in SFA, MUFA, and PUFA levels within the cell. ${ }^{36}$ One model is that CIL56 stimulates ACC activity, leading to the accumulation of malonyl-CoA. Malonyl-CoA is an endogenous negative regulator of $\mathrm{CPT}^{28}$ and inhibition of CPT1-dependent mitochondrial FA $\beta$-oxidation activity could account for the accumulation of multiple FA species in CIL56-treated cells. The accumulation of one or more FAs may be directly toxic itself, through direct effects on membrane-enclosed organelles or the plasma membrane. Alternatively or in parallel, the inhibition of mitochondrial $\beta$-oxidation may lead to the depletion of metabolites needed for cell survival (e.g., ATP). ${ }^{37}$ Although the precise target and mechanism of action of this lethal compound remains to be resolved, these results suggest that small molecule-mediated perturbations of FA metabolism can cause non-apoptotic RCD.

\section{Essential roles for lipids in the execution of non-apoptotic cell death}

The examples presented above suggest that FAs can in some contexts trigger non-apoptotic RCD. In this section, we consider examples where lipids are required for the execution of non-apoptotic RCD by acting as signaling molecules, modulators of lethal pathways, or essential nodes in the lethal pathways themselves.

Necroptosis. Necroptosis is a non-apoptotic form of RCD that is implicated in homeostatic and pathological cell death in the immune system, brain, and other tissues. ${ }^{38}$ Necroptosis can be induced by cytokines such as tumor necrosis factor-alpha (TNF- $a$ ). In the presence of caspase inhibitors, TNF- $a$ induces the formation of a multiprotein complex, called the necrosome, that promotes necroptosis. ${ }^{4}$ In this pathway, receptor-interacting serine/threonine-protein kinases 1 and 3 (RIPK1 and RIPK3) heterodimerize, leading to the recruitment of MLKL and its subsequent phosphorylation on T387 and S358 (in the human protein) by RIPK3. ${ }^{39}$ Once phosphorylated, MLKL translocates to the plasma membrane (as well as intracellular membranes), oligomerizes, and causes cell death (Figure 3a). ${ }^{40-43}$ Lipids are essential for this terminal process: charged amino acids in the N-terminal coiled-coil domain/4-helical bundle of phosphorylated MLKL bind specifically to membrane PIPs (Figure 1b). ${ }^{41-43}$ Based on studies performed using liposomes, MLKL oligomerization at the membrane is necessary and sufficient to cause membrane leakage, suggesting that in vivo MLKL oligomers may form a pore in the plasma membrane to cause the release of intracellular contents, loss of ionic homeostasis, and cellular rupture. ${ }^{41} \mathrm{PIPs}$, including $\mathrm{PI}(5) \mathrm{P}$ and $\mathrm{PI}(4,5) \mathrm{P}_{2}$, are required for MLKL membrane targeting, as liposomes containing only PIs, but not PIPs, do not exhibit MLKL-dependent leakage. ${ }^{41}$ Interestingly, specific MLKL mutants can be used to dissociate membrane binding from membrane permeabilization, suggesting that these processes are independent. ${ }^{43}$ Imaging studies in human cells reveal phosphorylated $\mathrm{MLKL}$ in discrete puncta, possibly indicating that membrane permeabilization is initiated at specific sites on the plasma membrane. ${ }^{41}$ Small molecule inhibitors that putatively block the formation of $\mathrm{PI}(5) \mathrm{P}$ by phosphoinositide kinase, FYVE finger containing (PIKfyve) protein, or the formation of $\mathrm{PI}(4,5) \mathrm{P}_{2}$ from $\mathrm{PI}(3,4,5) \mathrm{P}_{3}$ by phosphatase and tensin homolog (PTEN), partially suppress and delay TNF- $a$-induced necroptosis in mouse L929 cells, ${ }^{42}$ indicating that $\mathrm{PI}(5) \mathrm{P}$ and $\mathrm{PI}(4,5) \mathrm{P}_{2}$ may be the most potent MLKL-binding lipids. These results highlight lipid composition and phosphorylation status of specific membrane glycerophospholipids as key mediators of necroptosis.

Pyroptosis. Pyroptosis is a highly inflammatory form of nonapoptotic RCD triggered in immune cells in response to various pathogen-associated molecular patterns (PAMPs) and damage-associated molecular patterns (DAMPs), including bacterial proteins, cholesterol crystals, silica, asbestos, and extracellular ATP. ${ }^{44}$ PAMPs and DAMPs trigger the formation of multiprotein 'inflammasome' complexes that activate caspase- 1 or caspase- $4 / 5$ (caspase- 11 in mouse), ${ }^{45}$ 
a

Mechanism of necroptosis

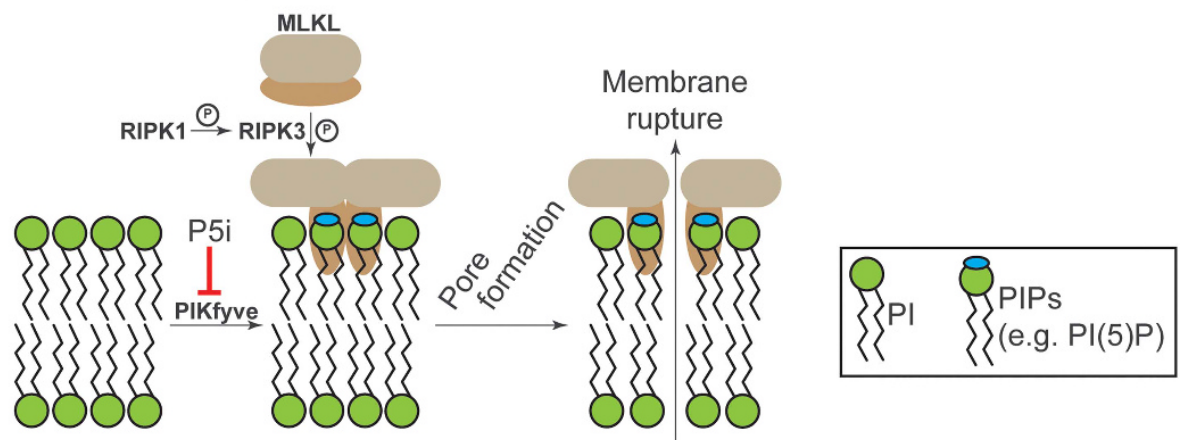

b

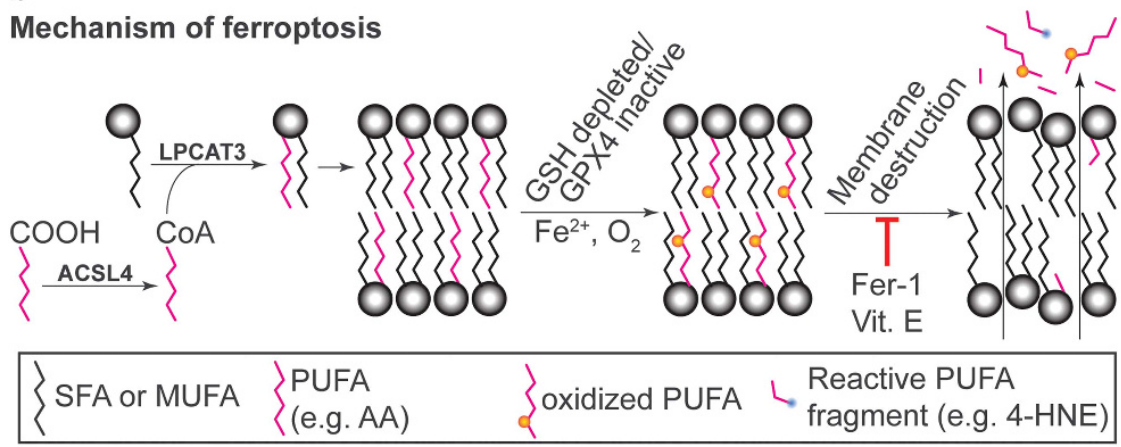

Figure 3 Role for lipids as executioners of non-apoptotic cell death. (a) Necroptosis involves the activation of RIPK1, which phosphorylates RIPK3 (denoted by the circled P), which then in turn phosphorylates MLKL. MLKL interacts with specific PIPs on lipid bilayers within the cell, including $\mathrm{PI}(5) \mathrm{P}$ and $\mathrm{PI}(4,5) \mathrm{P}_{2}$. The formation of PIPs from PIs requires various PI kinases such as PIKfyve. Phosphorylated MLKL undergoes a confirmational change that allows it to bind PIPs on the plasma membrane and, presumably, form a lethal membrane pore. The stoichiomety of the pore-forming MLKL oligomer is debated. (b) Ferroptosis requires membrane-resident PUFAs, depicted as pink chains, such as arachidonic acid (AA, 20:4n-6). For death to proceed, PUFAs must be acylated by acyl-CoA synthetase long-chain family member 4 (ACSL4) and inserted into lysophospholipids by lysophosphatidylcholine acyltransferase 3 (LPCAT3). Ferroptosis involves oxidation (orange dots) of membrane PUFAs. It is thought that this leads to fragmentation of these oxidized species, generating toxic aldehydes like 4-hydroxynonenal (4-HNE). Cell death is due to physical destruction of the membrane. Death can be prevented by synthetic or natural lipophilic antioxidants such as ferrostatin-1 (Fer-1) or vitamin $\mathrm{E}$ (Vit. E), respectively.

which in turn can promote the formation of membrane pores, loss of ionic balance, cell rupture, and release of intracellular contents, including inflammatory cytokines such as interleukin- $1 \beta .^{46}$ Gasdermin D was recently identified as a caspase-1/4/5/11 substrate that is essential for pyroptosis. ${ }^{47,48}$ The cleaved $\mathrm{N}$-terminal domain of gasdermin $\mathrm{D}$ is sufficient to trigger death, and one possibility is that this fragment acts at the membrane in a manner analogous to MLKL in necroptosis to form a membrane pore itself or to cause the oligomerization of other pore-forming proteins. If so, one prediction is that the interaction of the $\mathrm{N}$-terminal gasdermin $\mathrm{D}$ domain with membrane lipids would be essential for membrane permeation.

Although a role for lipids in the execution of pyroptosis remains speculative, stronger evidence exists to suggest a role for specific lipids as modulators of this process. For example, in mouse macrophages primed to undergo pyroptosis, inhibition of FASN-mediated de novo FA synthesis using the small molecule inhibitors cerulenin and C75 attenuates the assembly of the nucleotide-binding oligomerization domain (NOD)-like receptor 3 (NLRP3) inflammasome and caspase-1 activation. ${ }^{49}$ Conversely, exposure to exogenous palmitate can enhance NLRP3-dependent caspase-1 activation. ${ }^{50}$ Mechanistically, palmitate may promote inflammasome assembly and caspase- 1 activation indirectly, by serving as a substrate for CPT1-dependent mitochondrial $\beta$-oxidation, a process that leads to enhanced reactive oxygen species (ROS) production (a known inducer of inflammasomes). ${ }^{50,51}$ If this mechanism is important, then any change in intracellular FA metabolism that enhances $\beta$-oxidation may serve to promote inflammasome activation and cell death, while conditions that suppress FA production or catabolism would inhibit this mechanism.

Ferroptosis. Ferroptosis is an iron-dependent, oxidative form of non-apoptotic RCD that has been implicated in pathological cell death in brain, kidney, and heart tissues. ${ }^{6,52-56}$ Ferroptosis can be triggered by the depletion of intracellular glutathione or inhibition of the essential glutathione (GSH)-dependent lipid hydroperoxide detoxifying enzyme GPX4. ${ }^{57}$ Normally, GSH-dependent GPX4 activity reduces potentially toxic lipid peroxides $(\mathrm{L}-\mathrm{OOH})$ to non-toxic lipid alcohols $(\mathrm{L}-\mathrm{OH})$. The current working model is that once GPX4 is inactivated, $\mathrm{L}-\mathrm{OOH}$ s accumulate and interact with iron, resulting in iron-catalyzed formation of lipid radicals $\left(\mathrm{L}-\mathrm{O}^{\bullet}\right)$ that are lethal to the cell (Figure $\left.3 \mathrm{~b}\right) .^{52,57}$ Indeed, depletion of GSH or direct inhibition of GPX4 results in the iron-dependent accumulation of ROS, accumulation 
of lysophospholipids (i.e., glycerophophospholipids lacking one fatty acyl chain), and depletion of several PUFAs such as arachidonic acid (AA, 20:4n-6). ${ }^{52,54,57}$ The accumulation of lysophospholipids and the depletion of specific PUFAs suggest that specific oxidized PUFAs are cleaved from the glycerophospholipid backbones (e.g., possibly by phospholipase $\mathrm{A} 2^{54}$ ) and subsequently degraded or destroyed. Strikingly, deletion of ACSL4 or LPCAT3, which encode enzymes required for the reacylation of membrane lysolipids with AA and other PUFAs, prevents ferroptosis induced by GPX4 inactivation (Figure 3b). ${ }^{36}$ Thus, to proceed, ferroptosis requires $A A$ and likely other PUFAs prepositioned in the membrane to serve as targets for $\mathrm{O}_{2}$-mediated oxidation and iron-catalyzed free radical production. As would be predicted from this model, cells are protected from ferroptosis by exogenous small molecules that neutralize toxic lipid ROS or block the formation of lipid peroxyl radicals. This includes small molecule lipophilic antioxidants (trolox, butylated hydroxytoluene, ferrostatin-1) and iron chelators (deferoxamine, ciclopirox). ${ }^{6,58,59}$ Supplementation with the prenol lipid antioxidant vitamin E ( $a$-tocopherol) (Figure 1a) can prevent ferroptosis in cell culture ${ }^{58}$ and the endogenous levels of this lipid also presumably impacts the ability of the cell to undergo ferroptosis following GPX4 inactivation in vivo (e.g., Wortmann et al. ${ }^{60}$ and Saito et al. ${ }^{61}$ ).

A major question concerns how PUFA oxidation leads to ferroptotic cell death. To date, there is no evidence that ferroptosis involves formation of a protein-based pore, although this possibility cannot currently be excluded. Oxidative destruction of plasma membrane PUFAs may lead to the formation of gaps in the plasma membrane, resulting in loss of ionic homeostasis. Alternatively or in parallel, the accumulation of highly oxidized PUFAs (or derivative fragments thereof, such as 4-hydroxynonenal (4-HNE)) could directly inactivate essential intracellular proteins or trigger additional death-promoting events. ${ }^{62}$ Consistent with this latter possibility, high expression of three enzymes (AKR1C1, $A K R 1 C 2$, and $A K R 1 C 3$ ) that can detoxify reactive aldehydes such as $4-\mathrm{HNE}^{63}$ is associated with resistance to ferroptosis. ${ }^{62}$

A recent report demonstrates that expression of the tumor suppressor protein p53 can modulate the sensitivity to ferroptosis in vitro and in vivo. ${ }^{64}$ Wild-type p53 can enhance the expression of numerous lipid metabolic enzymes, including CPT1 and acyl-CoA dehydrogenase family member 11 (ACAD11), to promote FA oxidation, ${ }^{65,66}$ while mutant p53 can upregulate de novo FA synthesis genes including FASN, $S C D$, and multiple genes in the mevalonate pathway that contribute to the synthesis of cholesterol and various prenol lipids. ${ }^{67}$ While speculative, one possibility is that p53-dependent effects on lipid metabolism could modulate ferroptosis sensitivity by altering lipid metabolism or membrane lipid composition.

\section{Challenges and open questions}

Lipids have important and diverse roles as triggers and executioners of non-apoptotic RCD. There are a number of areas where significant gaps exist in our understanding of the link between lipids and non-apoptotic cell death, which we discuss below. Additionally, new technologies to manipulate, image and quantify lipids should help better understand the roles of specific lipids, lipid metabolic enzymes and lipid metabolic pathways in RCD (Box 1).

Understanding lethal pathways triggered by lipid accumulation. In most cases, how certain lipids activate specific non-apoptotic RCD pathways is not clear. For example, as noted above, the precise non-apoptotic RCD pathway that is activated by stimuli such as OA release from MFGs in mammary epithelial cells, or exposure to LPS+palmitate in macrophages, remains unclear. Likewise, glycerolipids with a single fatty acyl substituent (lysophosphatidylcholine and lysophosphatidic acid) trigger pyroptosis in human aortic endothelial cells though an unknown molecular mechanism. ${ }^{68}$

In a related vein, some stimuli trigger non-apoptotic death involving recognizable components of a specific pathway, but in an unusual or unexpected way. Thus, in human umbilical endothelial cells, palmitic acid induces a form of necroptosis that is RIPK3 dependent but RIPK1 independent, ${ }^{69}$ implying that this treatment can bypass the need for RIPK1 activation. Conversely, treatment of SH-SY5Y neuroblastoma cells and Jurkat cells with the oxysterol 24(S)-hydroxycholesterol (24S$\mathrm{OHC}$ ) leads to cell death that is RIPK1 dependent, but RIPK3 and MLKL independent. ${ }^{70-72}$ Further studies of these examples should help determine whether certain lipids engage truly novel lethal pathways or activate known non-apoptotic RCD pathways, but in unusual or cell type-specific ways.

Understanding context specificity and crosstalk. Depending on the context, the same lipid can have different roles in cell death. As described above, OA triggers lysosome-dependent non-apoptotic RCD in mammary epithelial cells, ${ }^{32}$ but acts to prevent apoptotic RCD in cells treated with high levels of palmitate or when mechanistic target of rapamycin (mTOR) signaling is aberrantly activated. ${ }^{73,74}$ Palmitate together with LPS induces a predominantly non-apoptotic cell death phenotype in macrophages, ${ }^{33}$ while in pancreatic cells, palmitate triggers apoptosis. ${ }^{75}$ Understanding how the same lipid can have opposing roles in different cell types is an important unsolved problem.

Disruption of lipid homeostasis may also connect two different lethal processes. In mouse erythroid precursor cells inactivation of GPX4, a canonical trigger for ferroptosis, ${ }^{57}$ leads to the accumulation of toxic lipid intermediates that covalently modify caspase- 8 and trigger necroptosis in the absence of death receptor stimulation. ${ }^{76}$ This suggests the existence of lipid-mediated crosstalk between the ferroptosis and necroptosis pathways. This link is likely cell-type specific, as canonical inhibitors of necroptosis do not block ferroptosis in a variety of cell lines ${ }^{6,54}$ and mouse embryonic fibroblasts lacking Ripk1, or mouse L929 fibrosarcoma cells where Ripk3 is depleted, are fully competent to undergo ferroptosis. ${ }^{54}$ In a related example, GPX4 inhibition can sensitize cancer cells to apoptosis induced by second mitochondrial-derived activator of caspases (SMAC) mimetics, ${ }^{77}$ connecting ferroptosis to apoptotic cell death pathways. Although more work is required to define these links, given the possibility that cells in vivo may be exposed to more than one lethal stimulus simultaneously, it will be important to investigate whether two lethal pathways 
Box 1 New tools and technologies for analyzing the role of lipids in cell death

a Genome-wide genetic screening

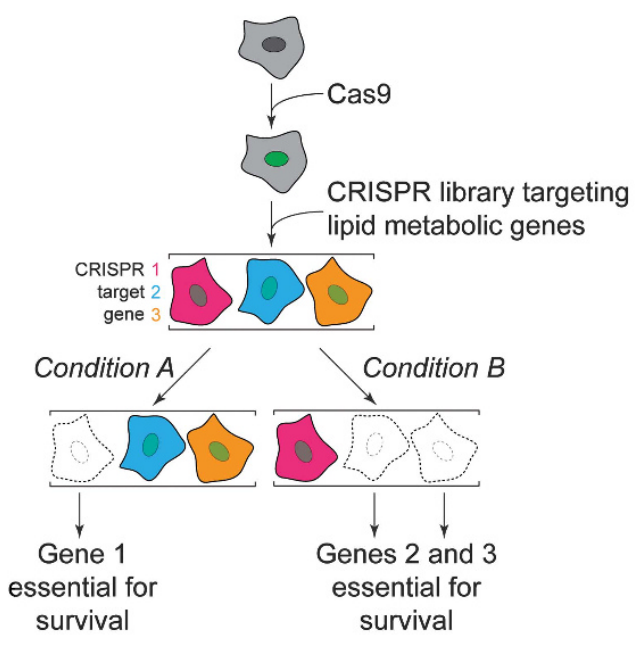

b

Metabolic network modelling

Human metabolic model (e.g. Recon 2)

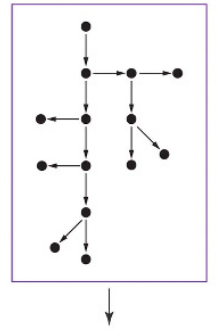

+ - Exogenous lipid

+/- Genetic perturbation, drug treatment

$\downarrow$

Predicted changes to levels of endogenous lipids and other metabolites
C

Lipid imaging in live cells<smiles>C#CCCCC(C)CC(=O)O</smiles>

17-octadecynoic acid

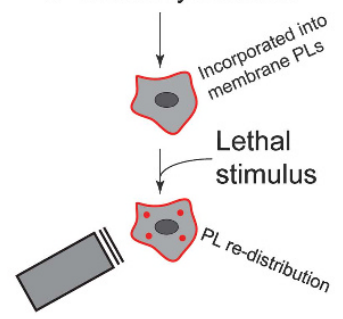

Stimulated Raman

scattering microscopy

(multiple images

over time) d

\section{Comparative lipidomics}

Treatment: $A$

Extract free fatty acids $\downarrow$

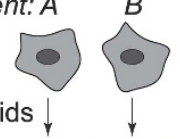

Label with stable isotope tags $124 \quad 127$

LC/MS/MS

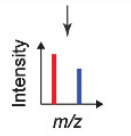

Free fatty acids labelled with stable isotope tag<smiles>[R]C(=O)OCc1ccc[n+](C)c1</smiles>

Compared with proteins and nucleic acids, the tools to investigate and manipulate lipids in the cell are historically less accurate, less sophisticated and less accessible. However, new tools and technologies are emerging that should help study the roles of lipids and lipid metabolism in RCD. Here, we provide four examples of how specific technologies could be used. (a) Pooled CRISPR/Cas9 genetic screening technology ${ }^{105}$ could be used to search for new modulators (enhancers or suppressors) of lipid-triggered non-apoptotic RCD (e.g., Condition $A=$ control and condition $B=$ lipid stimulation). (b) Computational reconstruction and modeling of metabolic networks in mammalian cells (e.g., using Recon 2, humanmetabolism.org $)^{106}$ could be used to predict the metabolic consequences of exogenous lipid addition or the effects of enzyme inactivation on the levels of various endogenous lipids in the cell. (c) The localization and fate of specific lipids or lipid-rich organelles (e.g., lipid droplets, LDs) in live versus dying cells could be interrogated kinetically in live cells using methods such as linear Raman imaging spectroscopy, ${ }^{107}$ coherent anti-Stokes Raman scattering microscopy, and stimulated Raman scattering (SRS) microscopy. ${ }^{108}$ For example, cells fed an alkyne-labeled fatty acid (17-octadececynoic acid) can incorporate this molecule into LDs and membrane phospholipids (PLs). The abundance and localization of labeled LDs and PLs can then be monitored inside the cell using SRS. ${ }^{108}$ (d) Advances in mass spectrometry-based lipidomics ${ }^{109-112}$ are enabling the identification of individual lipid species whose levels are perturbed in dying versus live cells. ${ }^{36,52,57} \mathrm{~A}$ related approach to monitor the relative abundance of different fatty acids (FAs) between samples involves post-lysis labeling of FAs with unique stable isotope tags (free fatty acid stable isotope tagging (FFAST)) whose mass differences can be resolved by LC-MS/MS. ${ }^{111}$ This advance could help improve the precision of comparative lipidomics comparing live and dying cells. 
can operate in parallel, whether lethal pathways are organized in some kind of hierarchy or whether activation of multiple pathways simultaneously generate new hybrid lethal pathways.

Understanding the role of lipid membrane repair. Membrane breaching occurs in all forms of RCD. In at least some cases, death-promoting stimuli activate both lethal and protective responses targeting the membrane. For example, bacterial pore-forming toxins (PFTs) such as aerolysin or Staphylococcus a-toxin cause $\mathrm{K}^{+}$efflux from the cell, which ultimately leads to inflammasome-dependent caspase-1dependent processing and nuclear translocation of the cholesterol and lipid biosynthetic master regulators sterolregulatory element-binding proteins 1 and 2 (SREBP1/2). ${ }^{78}$ SREBP1/2 upregulates transcription of FASN and HMGCR (encoding 3-hydroxy-3-methylglutaryl-CoA reductase, the rate-limiting enzyme required for cholesterol synthesis), resulting in the accumulation of cholesterol and other lipids. ${ }^{78}$ When SREBP1/2 processing is inhibited, cells are hypersensitized to PFT-induced cell death. ${ }^{78}$ Although it is not known how cholesterol and other lipids help the cell resist death, a plausible mechanism is that newly synthesized lipids are used to help stabilize or repair damaged membranes. Such a response would help ensure that cell death only proceeds in cells receiving a strong lethal stimulus, allowing damage due to 'accidental' exposures to be repaired.

Ultimately, to ensure cell death, processes that promote the stability and function of the membrane must be overcome. Different forms of acute membrane damage associated with non-apoptotic RCD, from mechanical damage to the insertion of bacterial PFTs into the membrane, are repaired by spontaneous membrane resealing for small diameter lesions $(<2 \mathrm{~nm})$ or $\mathrm{Ca}^{2+}$ influx-triggered repair for larger injuries. ${ }^{79}$ $\mathrm{Ca}^{2+}$-dependent repair involves a number of membrane-linked changes, including fusion with intracellular vesicles and organelles (e.g., lysosomes), endocytosis, protrusion or 'blebbing' of the membrane and exocytosis. ${ }^{79-81}$ These responses occur within seconds to minutes of membrane damage and represent the immediate attempt to prevent widespread loss of membrane homeostasis and eject damaged portions of the membrane (such as those containing bacterial PFTs or oxidatively damaged lipids) from the cell surface. One intriguing possibility is that non-apoptotic pathways subvert these immediate responses to membrane damage, thereby promoting death.

Understanding how modulation of lipid metabolism by other metabolic processes impacts cell death. An important goal is to better understand the links between nonapoptotic RCD and specific lipid metabolic pathways and processes. $^{82}$ The execution of ferroptosis, in particular, requires the uptake of glutamine and the production of citrate, processes that may support high rates of de novo lipid synthesis. ${ }^{6,55,83}$ More broadly, lipid storage organelles such as lipid droplets (LDs) and key lipid-modifying pathways such as autophagy may have roles as modulators of non-apoptotic RCD. LDs are dynamic structures that comprise a single membrane enclosing a core containing mostly neutral lipids (e.g., triacylglycerides, Figure 1a) and cholesterol esters.
Apoptosis-inducing agents, such as etoposide, inhibit mitochondrial $\beta$-oxidation and promote FA incorporation in LDs. ${ }^{84}$ Whether these organelles are linked to non-apoptotic RCD is unclear. However, in one example cited above, the treatment of SH-SY5Y neuroblastoma cells and Jurkat cells with $24 S-O H C$ leads to the acyl-CoA:cholesterol acyltransferase 1 (ACAT1)-dependent formation of LDs and toxic accumulation of esterified $24 \mathrm{~S}-\mathrm{OHC}$ derivatives, presumably in LDs. $^{70-72}$

Autophagy is a process of cellular 'self-digestion' that involves the formation of double-membrane intracellular vesicles that can fuse with lysosomes to degrade intracellular contents (i.e., protein and lipids). While controversial, in mammalian cells autophagy is generally thought to be protective rather than lethal. ${ }^{85,86}$ However, in human umbilical endothelial cells, treatment with palmitic acid is lethal and cell death is partially suppressed by inhibition of the autophagy genes VPS34 and ATG7. ${ }^{69}$ This suggests that autophagy may promote death in this context. Conversely, since the process of autophagy can consume lipids (i.e., lipophagy), ${ }^{87}$ it is intriguing to speculate that this process could prevent nonapoptotic RCD. For example, lipophagy could help maintain ATP levels under conditions that would normally lead to ATP depletion and necrotic cell death. ${ }^{88}$ Another possibility is that high levels of lipophagy could block non-apoptotic RCD by consuming key lipids or FAs that would otherwise trigger cell death.

Understanding cell non-autonomous effects. In addition to cell-autonomous roles in non-apoptotic RCD, lipids also have systemic roles in mediating cell death in vivo. For example, treatment of peritoneal macrophages with a chimeric toxin activates the NAIP5/NLRC4 inflammasome and leads to an eicosanoid storm, independent of cytokine production, that is acutely lethal to mice. ${ }^{89}$ Eicosanoids are paracrine signaling molecules, including prostaglandins and leukotrienes, derived from the oxidation of $A A$ by the cyclooxygenase and lipoxygenase pathways. ${ }^{90,91}$ Production of these molecules is highly upregulated during infection and eicosanoids act as both pro- and anti-inflammatory non-cell autonomous signals. ${ }^{92}$ During ferroptosis, oxidized derivatives of $\mathrm{AA}$, including 5-hydroxyeicosatetraenoic acid (5-HETE), 11-HETE, and 15-HETE, are released into the surrounding medium of dying cells. ${ }^{54}$ If ferroptosis also occurs in the body, then these molecules could likewise have important signaling roles, such as attracting immune cells to sites of tissue damage. ${ }^{93}$ In this manner, the release of oxidized lipid derivatives could have an analogous role to the externalization of PS during apoptosis, facilitating non-cell autonomous processes essential for the proper disposal of dead and dying cells.

Understanding the causes of pathological cell death. A number of inherited genetic disorders, including Niemann-Pick disease, cerebrotendinous xanthomatosis, hereditary spastic paraparesis type 5 , and a spectrum of peroxisomal $\beta$-oxidation disorders, are caused by mutations in specific lipid metabolic genes. These inborn errors of metabolism (IEMs) result in the accumulation of particular lipids and cell type-specific cell death, typically in the nervous system (Table 1). ${ }^{94-101}$ How 
Table 1 Examples of inherited disorders of lipid metabolism linked to cell death

\begin{tabular}{|c|c|c|c|}
\hline Disease & $\begin{array}{l}\text { OMIM } \\
\text { identifier }\end{array}$ & Gene & Lipid-dependent death phenotype \\
\hline Niemann-Pick disease (Types A, B) & $\begin{array}{l}257200 \\
607616\end{array}$ & SMPD1 & $\begin{array}{l}\text { Failure to catabolize sphingomyelin to ceramide in the lysosome. Leads } \\
\text { to neurodegeneration with death typically by age } 3 \text { (in Type A) and liver } \\
\text { disease in adulthood (in Type B) }\end{array}$ \\
\hline Niemann-Pick disease (Type C) & 257220 & $N P C 1, N P C 2$ & $\begin{array}{l}\text { Accumulation of cholesterol and glycerosphingolipids in endosomes } \\
\text { and lysosomes, leading to pathological cell death }\end{array}$ \\
\hline Hereditary spastic paraparesis type 5 & 270800 & CYP7B1 & $\begin{array}{l}\text { Defects in cholesterol metabolism, particularly the formation of } \\
\text { hydroxysteroids, with a corresponding accumulation of oxysteroid } \\
\text { precursors ( } 25 \text {-hydroxycholesterol) and degeneration of motor neurons }\end{array}$ \\
\hline Cerebrotendinous xanthomatosis & 213700 & CYP27A1 & $\begin{array}{l}\text { Defects in cholesterol metabolism leading to accumulation of toxic } \\
\text { cholesterol deposits in the cerebellum and other tissues }\end{array}$ \\
\hline Refsum disease & 266500 & $\mathrm{PHYH}$ & $\begin{array}{l}\text { Failure to metabolize phytanic acid (a bacterially-produced branched } \\
\text { chain lipid) in the peroxisome, leading to neuronal cell death }\end{array}$ \\
\hline $\begin{array}{l}\text { Peroxisome biogenesis disorder } 1 \mathrm{~A} \\
\text { (Zellweger) }\end{array}$ & 214100 & PEX1 & $\begin{array}{l}\text { Defects in peroxisome biogenesis leading to the accumulation of very } \\
\text { long chain fatty acids (VLCFAs, e.g., C26:0), neuronal cell death and } \\
\text { death before } 1 \text { year of age in severe cases }\end{array}$ \\
\hline Adrenoleukodystrophy & 300100 & $A B C D 1$ & $\begin{array}{l}\text { Defect in peroxisomal VLCFA metabolism leading to toxic VLCFA } \\
\text { accumulation, neuronal demyelination and death }\end{array}$ \\
\hline Krabbe disease & 245200 & GALC & $\begin{array}{l}\text { Defect in the catabolism of galactocerebrosides (sphingolipids con- } \\
\text { jugated to galactose) leading to the accumulation of specific sphingo- } \\
\text { lipids (e.g., psychosine), destruction of oligodendrocytes in the nervous } \\
\text { system and death by the age of two in severe cases }\end{array}$ \\
\hline
\end{tabular}

Inherited mutations in specific lipid metabolic genes can lead to the accumulation of particular lipids and pathological cell death. Eight examples are shown. In most cases, the type of cell death triggered by abnormal lipid accumulation is unclear. Further information can be found at the OMIM website (www.omim.org/).

lipid accumulation (or depletion) triggers death in these cells, and whether this involves apoptotic or non-apoptotic pathways, is generally not well understood. Additional studies of these disorders could unveil new mechanisms of lipidtriggered or lipid-mediated non-apoptotic RCD. For example, in a mouse model of Niemann-Pick disease Type C, a disease characterized by the aberrant accumulation of cholesterol and other lipids in endosomes and lysosomes due to mutations in Npc1, neuronal cell death is not prevented by transgenic expression of the anti-apoptotic protein $\mathrm{Bcl}-2$, suggesting that death could involve activation of a non-apoptotic pathway. ${ }^{102}$ Failure to repair oxidatively damaged lipids, due to mutations that impair the function of the GSH-GPX4 pathway, is another example of how disruption of normal lipid metabolism can impair organismal function ${ }^{61}$ and further study of these disorders could lead to additional insights into the regulation of ferroptotic cell death in vivo.

Treating disease. It may be possible to treat disease by modulating (enhancing or suppressing) specific nonapoptotic RCD pathways. Targeting the lipid-dependent aspects of these processes may provide novel routes to do so. For example, certain lung cancer cells can be induced to die via necroptosis by the sphingosine analog drug FTY720 (fingolimod) through a mechanism involving protein phosphatase $2 \mathrm{~A}$-dependent activation of RIPK1. ${ }^{103}$ One interesting prediction consistent with this result is that FTY720 might mimic the function of an endogenous lipid that normally promotes necroptosis to limit tumor formation. Drug repurposing may also open avenues to the manipulation of lipiddependent non-apoptotic RCD in humans. Two reports have suggested that it may be possible to induce ferroptosis, at least in some cells, using the multikinase inhibitor sorafenib and the antineoplastic agent altretamine..$^{62,104}$ Although sorafenib appears to trigger ferroptosis by blocking GSH synthesis, altretamine can directly inhibit GPX4. ${ }^{62,104}$ It remains to be seen whether evidence of ferroptosis can be found in patients receiving these drugs.

In addition to inducing cell death through modulation of lipid metabolism, inhibiting lipid-dependent processes may be useful in some contexts. For example, synthetic lipophilic antioxidants that inhibit ferroptosis have been shown to block pathological cell death in brain and kidney tissues. ${ }^{52,53}$ A better understanding of how lipids and lipid metabolism impact non-apoptotic RCD should allow for the development of improved therapies targeting these processes in the future. Quarato et al (Molecular Cell, Feb 18;61(4): 589-601) report that membrane $\mathrm{PI}(4,5) \mathrm{P} 2$ is the preferred binding partner for $\mathrm{MLKL}$ in cells undergoing necroptosis.

\section{Conflict of Interest}

The authors declare no conflict of interest.

Acknowledgements. SJD is supported by an R00 award (R00CA166517) from the National Cancer Institute (USA).

1. Ashkenazi A, Salvesen G. Regulated cell death: signaling and mechanisms. Annu Rev Cell Dev Biol 2014; 30: 337-356.

2. Fuchs Y, Steller H. Programmed cell death in animal development and disease. Cell 2011; 147: $742-758$.

3. Kroemer G, Galluzzi L, Vandenabeele P, Abrams J, Alnemri ES, Baehrecke EH et al. Classification of cell death: recommendations of the Nomenclature Committee on Cell Death 2009. Cell Death Differ 2009; 16: 3-11.

4. Degterev A, Huang Z, Boyce M, Li Y, Jagtap P, Mizushima N et al. Chemical inhibitor of nonapoptotic cell death with therapeutic potential for ischemic brain injury. Nat Chem Biol 2005; 1: 112-119.

5. Brennan MA, Cookson BT. Salmonella induces macrophage death by caspase-1dependent necrosis. Mol Microbiol 2000; 38: 31-40.

6. Dixon SJ, Lemberg KM, Lamprecht MR, Skouta R, Zaitsev EM, Gleason CE et al. Ferroptosis: an iron-dependent form of nonapoptotic cell death. Cell 2012; 149: 1060-1072.

7. Galluzzi L, Bravo-San Pedro JM, Vitale I, Aaronson SA, Abrams JM, Adam D et al Essential versus accessory aspects of cell death: recommendations of the NCCD 2015. Cell Death Differ 2014; 22: 58-73. 
8. Vanden Berghe $T$, Linkermann $A$, Jouan-Lanhouet $S$, Walczak $H$, Vandenabeele $P$. Regulated necrosis: the expanding network of non-apoptotic cell death pathways. Nat Rev Mol Cell Biol 2014; 15: 135-147.

9. Linkermann A, Stockwell BR, Krautwald S, Anders H-J. Regulated cell death and inflammation: an auto-amplification loop causes organ failure. Nat Rev Immunol 2014; 14 759-767.

10. Knobloch M, Braun SMG, Zurkirchen L, Schoultz von C, Zamboni N, Araúzo-Bravo MJ et al. Metabolic control of adult neural stem cell activity by Fasn-dependent lipogenesis. Nature 2013; 493: 226-230.

11. Atilla-Gokcumen GE, Muro E, Relat-Goberna J, Sasse S, Bedigian A, Coughlin ML et al. Dividing cells regulate their lipid composition and localization. Cell 2014; 156: 428-439.

12. Ma DK, Li Z, Lu AY, Sun F, Chen S, Rothe M et al. Acyl-CoA dehydrogenase drives heat adaptation by sequestering fatty acids. Cell 2015; 161: 1152-1163.

13. Fahy E, Cotter D, Sud M, Subramaniam S. Lipid classification, structures and tools. Biochim Biophys Acta 2011; 1811: 637-647

14. Fahy E, Subramaniam S, Murphy RC, Nishijima M, Raetz CRH, Shimizu T et al. Update of the LIPID MAPS comprehensive classification system for lipids. J Lipid Res 2009; 50: S9-14.

15. Cnop $M$, Ladrière L, Igoillo-Esteve $M$, Moura RF, Cunha DA. Causes and cures for endoplasmic reticulum stress in lipotoxic $\beta$-cell dysfunction. Diabetes Obes Metab 2010; 12 (Suppl 2): 76-82.

16. Obeid LM, Linardic CM, Karolak LA, Hannun YA. Programmed cell death induced by ceramide. Science 1993; 259: 1769-1771.

17. Mullen TD, Jenkins RW, Clarke CJ, Bielawski J, Hannun YA, Obeid LM. Ceramide synthasedependent ceramide generation and programmed cell death: involvement of salvage pathway in regulating postmitochondrial events. J Biol Chem 2011; 286: 15929-15942.

18. Del Solar V, Lizardo DY, Li N, Hurst JJ, Brais CJ, Atilla-Gokcumen GE. Differential regulation of specific sphingolipids in colon cancer cells during staurosporine-induced apoptosis. Chem Biol 2015; 22: 1662-1670.

19. Chipuk JE, McStay GP, Bharti A, Kuwana T, Clarke CJ, Siskind LJ et al. Sphingolipid metabolism cooperates with BAK and BAX to promote the mitochondrial pathway of apoptosis. Cell 2012; 148: 988-1000.

20. Kagan VE, Tyurin VA, Jiang J, Tyurina YY, Ritov VB, Amoscato AA et al. Cytochrome $c$ acts as a cardiolipin oxygenase required for release of proapoptotic factors. Nat Chem Biol 2005; 1: 223-232.

21. Kagan VE, Chu CT, Tyurina YY, Cheikhi A, Bayir H. Cardiolipin asymmetry, oxidation and signaling. Chem Phys Lipids 2014; 179: 64-69.

22. Tait SWG, Green DR. Mitochondria and cell death: outer membrane permeabilization and beyond. Nat Rev Mol Cell Biol 2010; 11: 621-632.

23. Suzuki J, Denning DP, Imanishi E, Horvitz HR, Nagata S. Xk-related protein 8 and CED-8 promote phosphatidylserine exposure in apoptotic cells. Science 2013; 341: 403-406.

24. Suzuki J, Imanishi E, Nagata S. Exposure of phosphatidylserine by Xk-related protein family members during apoptosis. J Biol Chem 2014; 289: 30257-30267.

25. Segawa K, Kurata S, Yanagihashi Y, Brummelkamp TR, Matsuda F, Nagata S. Caspasemediated cleavage of phospholipid flippase for apoptotic phosphatidylserine exposure. Science 2014; 344: 1164-1168.

26. Suzuki J, Umeda M, Sims PJ, Nagata S. Calcium-dependent phospholipid scrambling by TMEM16F. Nature 2010; 468: 834-838.

27. Baxter AA, Hulett MD, Poon IK. The phospholipid code: a key component of dying cell recognition, tumor progression and host-microbe interactions. Cell Death Differ 2015; 22 1893-1905.

28. Currie E, Schulze A, Zechner R, Walther TC, Farese RV. Cellular fatty acid metabolism and cancer. Cell Metab 2013; 18: 153-161.

29. Boya P, Kroemer G. Lysosomal membrane permeabilization in cell death. Oncogene 2008 27: 6434-6451.

30. Repnik U, Hafner Česen M, Turk B. Lysosomal membrane permeabilization in cell death: concepts and challenges. Mitochondrion 2014; 19: 49-57.

31. Kreuzaler PA, Staniszewska AD, Li W, Omidvar N, Kedjouar B, Turkson J et al. Stat3 controls lysosomal-mediated cell death in vivo. Nat Cell Biol 2011; 13: 303-309.

32. Sargeant TJ, Lloyd-Lewis B, Resemann HK, Ramos-Montoya A, Skepper J, Watson CJ. Stat 3 controls cell death during mammary gland involution by regulating uptake of milk fat globules and lysosomal membrane permeabilization. Nat Cell Biol 2014; 16: 1057-1068.

33. Schilling JD, Machkovech HM, He L, Diwan A, Schaffer JE. TLR4 activation under lipotoxic conditions leads to synergistic macrophage cell death through a TRIF-dependent pathway. J Immunol 2013; 190: 1285-1296.

34. Weber K, Schilling JD. Lysosomes integrate metabolic-inflammatory cross-talk in primary macrophage inflammasome activation. J Biol Chem 2014; 289: 9158-9171.

35. Feldstein AE, Werneburg NW, Li Z, Bronk SF, Gores GJ. Bax inhibition protects against free fatty acid-induced lysosomal permeabilization. Am J Physiol Gastrointest Liver Physiol 2006; 290: G1339-46.

36. Dixon SJ, Winter GE, Musavi LS, Lee ED, Snijder B, Rebsamen M et al. Human haploid cell genetics reveals roles for lipid metabolism genes in nonapoptotic cell death. ACS Chem Biol 2015; 10: 1604-1609.

37. Pike LS, Smift AL, Croteau NJ, Ferrick DA, Wu M. Inhibition of fatty acid oxidation by etomoxir impairs NADPH production and increases reactive oxygen species resulting in ATP depletion and cell death in human glioblastoma cells. Biochim Biophys Acta 2011 1807: $726-734$

38. Zhou W, Yuan J. Necroptosis in health and diseases. Semin Cell Dev Biol 2014; 35: 14-23.
39. Sun L, Wang H, Wang Z, He S, Chen S, Liao D et al. Mixed lineage kinase domain-like protein mediates necrosis signaling downstream of RIP3 kinase. Cell 2012; 148: 213-227.

40. Chen X, Li W, Ren J, Huang D, He W-T, Song Y et al. Translocation of mixed lineage kinase domain-like protein to plasma membrane leads to necrotic cell death. Cell Res 2014; 24 : 105-121.

41. Wang H, Sun L, Su L, Rizo J, Liu L, Wang L-F et al. Mixed lineage kinase domain-like protein MLKL causes necrotic membrane disruption upon phosphorylation by RIP3. Mol Cell 2014; 54: 133-146.

42. Dondelinger Y, Declercq W, Montessuit S, Roelandt R, Goncalves A, Bruggeman I et al. MLKL compromises plasma membrane integrity by binding to phosphatidylinositol phosphates. Cell Rep 2014; 7: 971-981.

43. Hildebrand JM, Tanzer MC, Lucet IS, Young SN, Spall SK, Sharma P et al. Activation of the pseudokinase MLKL unleashes the four-helix bundle domain to induce membrane localization and necroptotic cell death. Proc Natl Acad Sci USA 2014; 111. 15072-15077

44. Bergsbaken T, Fink SL, Cookson BT. Pyroptosis: host cell death and inflammation. Nat Rev Microbiol 2009; 7: 99-109.

45. de Zoete MR, Palm NW, Zhu S, Flavell RA. Inflammasomes. Cold Spring Harb Perspect Biol 2014; 6: a016287.

46. Fink SL, Cookson BT. Caspase-1-dependent pore formation during pyroptosis leads to osmotic lysis of infected host macrophages. Cell Microbiol 2006; 8: 1812-1825.

47. Kayagaki N, Stowe IB, Lee BL, O'Rourke K, Anderson K, Warming S et al. Caspase-11 cleaves gasdermin D for non-canonical inflammasome signalling. Nature 2015; $\mathbf{5 2 6}$ : 666-671.

48. Shi J, Zhao $\mathrm{Y}$, Wang $\mathrm{K}$, Shi $\mathrm{X}$, Wang $\mathrm{Y}$, Huang $\mathrm{H}$ et al. Cleavage of GSDMD by inflammatory caspases determines pyroptotic cell death. Nature 2015; 526: 660-665.

49. Moon J-S, Lee S, Park M-A, Siempos II, Haslip M, Lee PJ et al. UCP2-induced fatty acid synthase promotes NLRP3 inflammasome activation during sepsis. J Clin Invest 2015; 125: 665-680.

50. Wen H, Gris D, Lei Y, Jha S, Zhang L, Huang MT-H et al. Fatty acid-induced NLRP3-ASC inflammasome activation interferes with insulin signaling. Nat Immunol 2011; 12: 408-415.

51. Zhou R, Yazdi AS, Menu P, Tschopp J. A role for mitochondria in NLRP3 inflammasome activation. Nature 2011; 469: 221-225.

52. Skouta R, Dixon SJ, Wang J, Dunn DE, Orman M, Shimada K et al. Ferrostatins inhibit oxidative lipid damage and cell death in diverse disease models. J Am Chem Soc 2014; 136: $4551-4556$.

53. Linkermann A, Skouta R, Himmerkus N, Mulay SR, Dewitz C, De Zen F et al. Synchronized renal tubular cell death involves ferroptosis. Proc Natl Acad Sci USA 2014; 111 16836-16841.

54. Friedmann Angeli JP, Schneider M, Proneth B, Tyurina YY, Tyurin VA, Hammond VJ et al. Inactivation of the ferroptosis regulator Gpx4 triggers acute renal failure in mice. Nat Cell Biol 2014; 16: 1180-1191.

55. Gao M, Monian P, Quadri N, Ramasamy R, Jiang X. Glutaminolysis and transferrin regulate ferroptosis. Mol Cell 2015; 59: 298-308.

56. Yang WS, Stockwell BR. Ferroptosis: death by lipid peroxidation. Trends Cell Biol 2016; 26: 165-176.

57. Yang WS, SriRamaratnam R, Welsch ME, Shimada K, Skouta R, Viswanathan VS et al Regulation of ferroptotic cancer cell death by GPX4. Cell 2014; 156: 317-331.

58. Yagoda N, Rechenberg von M, Zaganjor E, Bauer AJ, Yang WS, Fridman DJ et al. RASRAF-MEK-dependent oxidative cell death involving voltage-dependent anion channels. Nature 2007; 447: 864-868.

59. Yang WS, Stockwell BR. Synthetic lethal screening identifies compounds activating irondependent, nonapoptotic cell death in oncogenic-RAS-harboring cancer cells. Chem Biol 2008; 15: 234-245

60. Wortmann M, Schneider M, Pircher J, Hellfritsch J, Aichler M, Vegi $\mathrm{N}$ et al. Combined deficiency in glutathione peroxidase 4 and vitamin $\mathrm{E}$ causes multiorgan thrombus formation and early death in mice. Circ Res 2013; 113: 408-417.

61. Saito Y, Shichiri M, Hamajima T, Ishida N, Mita Y, Nakao S et al. Enhancement of lipid peroxidation and its amelioration by vitamin $E$ in a subject with mutations in the SBP2 gene. $J$ Lipid Res 2015; 56: 2172-2182.

62. Dixon SJ, Patel DN, Welsch M, Skouta R, Lee ED, Hayano M et al. Pharmacological inhibition of cystine-glutamate exchange induces endoplasmic reticulum stress and ferroptosis. Elife 2014; 3: e02523.

63. Burczynski ME, Sridhar GR, Palackal NT, Penning TM. The reactive oxygen species-and Michael acceptor-inducible human aldo-keto reductase AKR1C1 reduces the alpha,betaunsaturated aldehyde 4-hydroxy-2-nonenal to 1,4-dihydroxy-2-nonene. J Biol Chem 2001; 276: $2890-2897$

64. Jiang L, Kon N, Li T, Wang S-J, Su T, Hibshoosh H et al. Ferroptosis as a p53-mediated activity during tumour suppression. Nature 2015; 520: 57-62.

65. Goldstein I, Rotter V. Regulation of lipid metabolism by p53 - fighting two villains with one sword. Trends Endocrinol Metab 2012; 23: 567-575.

66. Jiang D, LaGory EL, Kenzelmann Broz D, Bieging KT, Brady CA, Link N et al. Analysis of p53 transactivation domain mutants reveals Acad11 as a metabolic target important for p53 pro-survival function. Cell Rep 2015; 10: 1096-1109.

67. Freed-Pastor WA, Mizuno H, Zhao X, Langerød A, Moon S-H, Rodriguez-Barrueco R et al. Mutant p53 disrupts mammary tissue architecture via the mevalonate pathway. Cell 2012; 148: 244-258 
68. Lopez-Pastrana J, Ferrer LM, Li Y-F, Xiong X, Xi H, Cueto R et al. Inhibition of caspase-1 activation in endothelial cells improves angiogenesis: a novel therapeutic potential for ischemia. J Biol Chem 2015; 290: 17485-17494.

69. Khan MJ, Rizwan Alam M, Waldeck-Weiermair M, Karsten F, Groschner L, Riederer M et al. Inhibition of autophagy rescues palmitic acid-induced necroptosis of endothelial cells. J Biol Chem 2012; 287: 21110-21120.

70. Yamanaka K, Saito Y, Yamamori T, Urano Y, Noguchi N. 24(S)-hydroxycholesterol induces neuronal cell death through necroptosis, a form of programmed necrosis. J Biol Chem 2011; 286: 24666-24673.

71. Yamanaka K, Urano Y, Takabe W, Saito Y, Noguchi N. Induction of apoptosis and necroptosis by 24(S)-hydroxycholesterol is dependent on activity of acyl-CoA:cholesterol acyltransferase 1. Cell Death Dis 2014; 5: e990.

72. Vo D-KH, Urano Y, Takabe W, Saito Y, Noguchi N. 24(S)-Hydroxycholesterol induces RIPK1-dependent but MLKL-independent cell death in the absence of caspase-8. Steroids 2015; 99: 230-237.

73. Listenberger LL, Han X, Lewis SE, Cases S, Farese RV, Ory DS et al. Triglyceride accumulation protects against fatty acid-induced lipotoxicity. Proc Natl Acad Sci USA 2003; 100: 3077-3082

74. Young RM, Ackerman D, Quinn ZL, Mancuso A, Gruber M, Liu L et al. Dysregulated mTORC1 renders cells critically dependent on desaturated lipids for survival under tumorlike stress. Genes Dev 2013; 27: 1115-1131.

75. Paumen MB, Ishida Y, Muramatsu M, Yamamoto M, Honjo T. Inhibition of carnitine palmitoyltransferase I augments sphingolipid synthesis and palmitate-induced apoptosis. J Biol Chem 1997; 272: 3324-3329.

76. Canli Ö, Alankuş YB, Grootjans S, Vegi N, Hültner L, Hoppe PS et al. Glutathione peroxidase 4 prevents necroptosis in mouse erythroid precursors. Blood 2015; 127: $139-48$.

77. Schoeneberger H, Belz K, Schenk B, Fulda S. Impairment of antioxidant defense via glutathione depletion sensitizes acute lymphoblastic leukemia cells for Smac mimeticinduced cell death. Oncogene 2015; 34: 4032-4043.

78. Gurcel L, Abrami L, Girardin S, Tschopp J, van der Goot FG. Caspase-1 activation of lipid metabolic pathways in response to bacterial pore-forming toxins promotes cell survival. Cell 2006; 126: 1135-1145.

79. Cooper ST, McNeil PL. Membrane Repair: Mechanisms and Pathophysiology. Physiol Rev 2015; 95: 1205-1240.

80. Babiychuk EB, Monastyrskaya K, Potez S, Draeger A. Blebbing confers resistance against cell lysis. Cell Death Differ 2011; 18: 80-89.

81. Scheffer LL, Sreetama SC, Sharma N, Medikayala S, Brown KJ, Defour et al. Mechanism of $\mathrm{Ca}^{2+}$-triggered ESCRT assembly and regulation of cell membrane repair. Nat Commun 2014; 5: 5646

82. Green DR, Galluzzi L, Kroemer G. Cell biology. Metabolic control of cell death. Science 2014; 345: 1250256.

83. DeBerardinis RJ, Mancuso A, Daikhin E, Nissim I, Yudkoff M, Wehrli S et al. Beyond aerobic glycolysis: transformed cells can engage in glutamine metabolism that exceeds the requirement for protein and nucleotide synthesis. Proc Natl Acad Sci USA 2007; 104: 19345-19350.

84. Boren J, Brindle KM. Apoptosis-induced mitochondrial dysfunction causes cytoplasmic lipid droplet formation. Cell Death Differ 2012; 19: 1561-1570.

85. Lum JJ, Bauer DE, Kong M, Harris MH, Li C, Lindsten T et al. Growth factor regulation of autophagy and cell survival in the absence of apoptosis. Cell 2005; 120: 237-248.

86. Shen S, Kepp O, Michaud M, Martins I, Minoux H, Métivier D et al. Association and dissociation of autophagy, apoptosis and necrosis by systematic chemical study. Oncogene 2011; 30: 4544-4556.

87. Singh R, Kaushik S, Wang Y, Xiang Y, Novak I, Komatsu M et al. Autophagy regulates lipid metabolism. Nature 2009; 458: 1131-1135.

88. Liu K, Czaja MJ. Regulation of lipid stores and metabolism by lipophagy. Cell Death Differ 2013; 20: 3-11.

89. Moltke, von J, Trinidad NJ, Moayeri M, Kintzer AF, Wang SB, van Rooijen N et al. Rapid induction of inflammatory lipid mediators by the inflammasome in vivo. Nature 2012; 490: 107-111.

90. Haeggström JZ, Funk CD. Lipoxygenase and leukotriene pathways: biochemistry, biology, and roles in disease. Chem Rev 2011; 111: 5866-5898.

91. Rouzer CA, Marnett LJ. Endocannabinoid oxygenation by cyclooxygenases, lipoxygenases, and cytochromes P450: cross-talk between the eicosanoid and endocannabinoid signaling pathways. Chem Rev 2011; 111: 5899-5921.

92. Dennis EA, Norris PC. Eicosanoid storm in infection and inflammation. Nat Rev Immunol 2015; 15: 511-523.
93. Powell WS, Rokach J. The eosinophil chemoattractant 5-oxo-ETE and the OXE receptor. Prog Lipid Res 2013; 52: 651-665.

94. Abe Y, Honsho M, Nakanishi H, Taguchi R, Fujiki Y. Very-long-chain polyunsaturated fatty acids accumulate in phosphatidylcholine of fibroblasts from patients with Zellweger syndrome and acyl-CoA oxidase1 deficiency. Biochim Biophys Acta 2014; 1841 610-619.

95. Theofilopoulos S, Griffiths WJ, Crick PJ, Yang S, Meljon A, Ogundare M et al. Cholestenoic acids regulate motor neuron survival via liver $X$ receptors. J Clin Invest 2014; 124: 4829-4842.

96. Gabandé-Rodríguez E, Boya P, Labrador V, Dotti CG, Ledesma MD. High sphingomyelin levels induce lysosomal damage and autophagy dysfunction in Niemann Pick disease type A. Cell Death Differ 2014; 21: 864-875.

97. Kirkegaard T, Roth AG, Petersen NHT, Mahalka AK, Olsen OD, Moilanen I et al. Hsp70 stabilizes lysosomes and reverts Niemann-Pick disease-associated lysosomal pathology. Nature 2010; 463: 549-553.

98. Moles A, Tarrats N, Fernández-Checa JC, Marí M. Cathepsin B overexpression due to acid sphingomyelinase ablation promotes liver fibrosis in Niemann-Pick disease. J Biol Chem 2012; 287: 1178-1188

99. Reiser G, Schönfeld P, Kahlert S. Mechanism of toxicity of the branched-chain fatty acid phytanic acid, a marker of Refsum disease, in astrocytes involves mitochondrial impairment. Int J Dev Neurosci 2006; 24: 113-122.

100. Hein S, Schönfeld P, Kahlert S, Reiser G. Toxic effects of X-linked adrenoleukodystrophyassociated, very long chain fatty acids on glial cells and neurons from rat hippocampus in culture. Hum Mol Genet 2008; 17: 1750-1761.

101. Ordonez MP, Roberts EA, Kidwell CU, Yuan SH, Plaisted WC, Goldstein LSB. Disruption and therapeutic rescue of autophagy in a human neuronal model of Niemann Pick type C1. Hum Mol Genet 2012; 21: 2651-2662.

102. Erickson RP, Bernard O. Studies on neuronal death in the mouse model of Niemann-Pick C disease. J Neurosci Res 2002; 68: 738-744.

103. Saddoughi SA, Gencer S, Peterson YK, Ward KE, Mukhopadhyay A, Oaks J et al. Sphingosine analogue drug FTY720 targets I2PP2A/SET and mediates lung tumour suppression via activation of PP2A-RIPK1-dependent necroptosis. EMBO Mol Med 2013; 5: 105-121.

104. Woo JH, Shimoni Y, Yang WS, Subramaniam P, lyer A, Nicoletti $P$ et al. Elucidating compound mechanism of action by network perturbation analysis. Cell 2015; 162: 441-451.

105. Shalem O, Sanjana NE, Hartenian E, Shi X, Scott DA, Mikkelsen TS et al. Genome-scale CRISPR-Cas9 knockout screening in human cells. Science 2014; 343: 84-87.

106. Thiele I, Swainston N, Fleming RMT, Hoppe A, Sahoo S, Aurich MK et al. A communitydriven global reconstruction of human metabolism. Nat Biotechnol 2013; 31: 419-425.

107. Majzner K, Kochan K, Kachamakova-Trojanowska N, Maslak E, Chlopicki S, Baranska M. Raman imaging providing insights into chemical composition of lipid droplets of different size and origin: in hepatocytes and endothelium. Anal Chem 2014; 86: 6666-6674.

108. Wei L, Hu F, Shen Y, Chen Z, Yu Y, Lin C-C et al. Live-cell imaging of alkyne-tagged small biomolecules by stimulated Raman scattering. Nat Methods 2014; 11: 410-412.

109. Köberlin MS, Snijder B, Heinz LX, Baumann CL, Fauster A, Vladimer Gl et al. A conserved circular network of coregulated lipids modulates innate immune responses. Cell 2015; 162 $170-183$

110. Astarita G, Kendall AC, Dennis EA, Nicolaou A. Targeted lipidomic strategies for oxygenated metabolites of polyunsaturated fatty acids. Biochim Biophys Acta 2015; 1851: 456-468.

111. Narayana VK, Tomatis VM, Wang T, Kvaskoff D, Meunier FA. Profiling of free fatty acids using stable isotope tagging uncovers a role for saturated fatty acids in neuroexocytosis. Chem Biol 2015; pii: S1074-5521(15)00373-7.

112. Muro E, Atilla-Gokcumen GE, Eggert US. Lipids in cell biology: how can we understand them better? Mol Biol Cell 2014; 25: 1819-1823.

This work is licensed under a Creative Commons

Attribution 4.0 International License. The images or other third party material in this article are included in the article's Creative Commons license, unless indicated otherwise in the credit line; if the material is not included under the Creative Commons license, users will need to obtain permission from the license holder to reproduce the material. To view a copy of this license, visit http:// creativecommons.org/licenses/by/4.0/ 